\title{
$\underline{\mathbf{P}-109}$
}

\section{Cell Apoptotic Determination by Annexin V-FITC Assay in Apigenin and Rutin-Induced Cell Death in Breast Cancer Cells}

\author{
Kamaludin $\mathrm{R}^{1,{ }^{*}}$, Froemming $\mathrm{GA}^{1,2}$, Ibahim $\mathrm{MJ}^{1,2}$ and Narimah $\mathrm{AHH}^{2}$ \\ ${ }^{1}$ Institute of Medical Molecular Biotechnology; ${ }^{2}$ Department of Biochemistry \& Molecular Medicine, Faculty of \\ Medicine, Universiti Teknologi MARA, Jalan Hospital, 47000 Sungai Buloh, Selangor, Malaysia; \\ E-mail: cerimerah@yahoo.com
}

Cells apoptosis is characterized by chromatin condensation, cell shrinkage and intact membrane blebbing. The translocation of phosphotidylserine (PS) from the inner membrane leaflets to the outer layer serves as a critical event during apoptosis. Annexin V-FITC is a fluorescent probe which binds to PS in a $\mathrm{Ca}^{2+}$-dependent pathway. Once on the membrane surface, these PS are able to bind to the annexin V-FITC conjugate protein. Propium Iodide (PI) vital staining is then performed to demonstrate whether the membrane integrity has been preserved or become totally compromised. Thus we aim to determine the cell death mechanism induced by apigenin and rutin on estrogen receptor-positive breast cancer cells, MCF-7 as compared to normal breast cells, MCF-10A using the above method. Tamoxifen was used as positive control. $1 \times 10^{6}$ cells $/ \mathrm{ml}$ were treated separately with apigenin, rutin and tamoxifen at $\mathrm{IC}_{50}$ concentrations of $34 \mu \mathrm{M}, 46 \mu \mathrm{M}$ and $30 \mu \mathrm{M}$ respectively, for 72 hours. Cells were then stained with annexin V and PI. The apoptotic cells (annexin positive and PI-negative) were differentiated from necrotic cells (annexin- and PI-positive) using flow cytometry. MCF-7 treated with apigenin, rutin and tamoxifen showed higher annexinpositive/PI-negative value i.e., apoptosis with $48 \%(\mathrm{p}<0.05, \mathrm{n}=3), 47 \%(\mathrm{p}<0.05, \mathrm{n}=3)$ and $51 \%(\mathrm{p}<0.05, \mathrm{n}=3)$ respectively, as compared to MCF-10A 9\% $(\mathrm{p}<0.05, \mathrm{n}=3), 13 \%(\mathrm{p}<0.05, \mathrm{n}=3)$ and $45 \%(\mathrm{p}<0.05, \mathrm{n}=3)$ respectively $)$. However, all these compounds were not cytotoxic to both cells. Therefore, our findings indicated that both apigenin and rutin were more potent as apoptosis inducing agents in MCF-7 as compared to MCF-10A. Further studies need to be conducted to further understand the apoptotic signaling pathways induced by both compounds in breast cancer cells. 